\title{
CORROSION RESISTANCE OF DECORATIVE CHROMIUM FILMS OBTAINED FROM TRIVALENT CHROMIUM SOLUTIONS
}

\author{
O.J SUAREZ ${ }^{*}$, J.J OLAYA ${ }^{1}$, M.F SUAREZ ${ }^{1}$, S.E. RODIL ${ }^{2}$ \\ Universidad Nacional de Colombia, Bogotá, Colombia. Ciudad universitaria edificio de posgrado de materiales. Bogotá-Colombia. \\ ${ }^{2}$ Instituto de Investigaciones en Materiales, Universidad Nacional Autónoma de México, México D.F.-Mexico.
}

(Received: March 1, 2011 - Accepted: October 12, 2011)

\begin{abstract}
In this work, the resistance to corrosion of chromium films obtained from trivalent chromium solutions of different compositions and the influence of solution compounds on the coatings electrochemical behavior and the microstructure were studied. The chromium coatings were obtained from trivalent solutions in a chloride-based bath with different complexing agents adding also sodium hypophosphite and aluminum chloride. UV-vis spectroscopy was carried out on all solutions before and after plating to observe changes in the chromium complexes chemical state due to the plating process. Scanning Electron Microscopy (SEM) and Energy Dispersive X-ray (EDX) were performed to examine the coatings surface morphology and composition; respectively. The coulometric method was used for measuring coating thickness. Electrochemical impedance spectroscopy (EIS) was done using 3\% $\mathrm{NaCl}$ as electrolyte and using a three-electrode cell with a standard calomel electrode (SCE) as reference. Bright chromium films were obtained from all baths however, differences were observed concerning morphology, thickness and corrosion resistance depending on the composition of the forming solution.
\end{abstract}

Keywords: Trivalent chromium, plating, microstructure, corrosion resistance.

\section{INTRODUCCION}

Chromium deposits obtained by electrolysis are of great importance in the field of decorative and industrial coatings; however, conventional hexavalent chromium solutions raised serious drawbacks from an environmental and occupational health point of view [1]. Alternatively trivalent chromium chemistry-based processes have been developed to reduce the problems associated with hexavalent chromium. Such processes have not been fully implemented in an industrial environment because of their higher maintenance costs and incomplete technological knowledge [2-3].

Chromium metal cannot be directly obtained from a solution of $\mathrm{Cr}^{+3}$ sulfates or chlorides since they form stable and inert complexes with $\mathrm{OH}^{-}, \mathrm{SO}_{4}^{-}$ 2 and $\mathrm{Cl}^{-}$ions and oxides during deposition which interfer with the cathodic reaction. Chromium should then form a complex with a compound (ligand) that can easily slide the $\mathrm{Cr}^{+3}$ ions and thus lead to its reduction to $\mathrm{Cr}^{0}$ [4-7]. The main complexing agents are: sodium hypophosphite and glycine, as well as other chelating agents such carboxylic acids or salts, urea, thiourea, thiocyanates, dimethylformamide, hydracine or hydroxyl-aminophosphates [2-10].

Song and Chin [6] have used chromium chloride solutions, with sodium and ammonium formate and acetate as complexants, thereby obtaining chromium coatings and it has been shown experimentally that complexing agents are actively involved in the $\mathrm{Cr}^{+3}$ reduction reactions. Surviliene et al [9] and Boasong et al [10] have found that some elements present as compounds in the solutions such as oxygen, carbon and phosphorus are incorporated into the coatings and thus modify their structure.

Baral [8], Baosong [10] and Survilliene [9,11] have studied the effect of the operating conditions such as the $\mathrm{pH}$, temperature, current density and adding agents on the cathodic efficiency, morphology and structure of deposits, obtaining a response variable dependence in all cases.

Other authors have reported the effect of reaction conditions during $\mathrm{Cr}^{+3}$ complexation in previous works [2-3], as well as the effect of sodium formate and acetate present in the solution on the chromium film morphology and corrosion resistance. In this work sodium hypophosphite and aluminum chloride were added to the basic formate and formate plus acetate baths to study the electrochemical behavior of the chromium films. Electrochemical impedance spectroscopy (EIS) was used to study the electrochemical behavior of the chromium coatings. The coating morphology and composition were studied by Scanning electron microscopy (SEM) and Energy dispersive X-ray (EDX) and films thickness was measured by the coulometric method [12] which also allow us to calculate the cathode efficiency.

\section{EXPERIMENTAL DETAILS}

2.1 Experimental design

The underlying goal of this study was to correlate chromium coating corrosion resistance to a set of factors such as: complexing, addition agents and time exposition to a corrosive environment. The Minitab software was used for designing and analyzing the experiments; Variance analysis (ANOVA) was used for analyzing the experimental results. The experimental order was randomized to ensure against the effect of time-related variables and also to satisfy statistical requirements independence of the observations. Each experiment was carried out with two replicates, until experiments were completed according to the design layout.

\subsection{Electroplating}

All chemicals used were Sigma Aldrich reagent grade. Solutions were formulated with chromium chloride $\left(\mathrm{CrCl}_{3} \cdot 6 \mathrm{H}_{2} \mathrm{O}\right)$ as chromium source in the quantities presented in Table 1 ; sodium formate ( $\mathrm{HCOONa}$ ) and sodium acetate $\left(\mathrm{CH}_{3} \mathrm{COONa} \cdot 3 \mathrm{H}_{2} \mathrm{O}\right)$ were used as complexants in 1:1 molar concentration regarding $\mathrm{Cr}$ in solution, $50 \mathrm{~g} / \mathrm{L}$ boric acid $\left(\mathrm{H}_{3} \mathrm{BO}_{3}\right)$ was used as buffer and sodium hypophosphite $\left(\mathrm{H}_{2} \mathrm{NaPO}_{2} \cdot \mathrm{H}_{2} \mathrm{O}\right)$ and aluminum chloride $\left(\mathrm{AlCl}_{3} \cdot 6 \mathrm{H}_{2} \mathrm{O}\right)$ as complexation and buffer assistant, respectively. Solutions were heated to $60^{\circ} \mathrm{C}$ for three hours during complexation reaction as in [2], and $\mathrm{pH}$ was adjusted to 3.5 units with sodium hydroxide.

The coatings were deposited on a $2 \times 2 \mathrm{~cm}^{2}$ mild steel (AISI 1008) flat sample. Preparation for all specimens was as follow: Firstly, the surface was mechanically polished using different grade emery paper up 600 (to simulate industrial conditions) and then manual and anodically degreased in sodium hydroxide $(5 \% \mathrm{w} / \mathrm{v})$, after having been activated in sulfuric acid $(5 \% \mathrm{w} / \mathrm{v})$ for 2 minutes and finally plated in a Watts nickel-plating bath to obtain 6 microns $\mathrm{Ni}$ thickness. Nickel layer is used in industry as previous film before chromium in decorative chromium coating because it provides a high bright surface [13]. Deionized water was used for rinsing the samples between all steps. Watts nickel-plating bath was used with a saccharine and thiourea brightener system; complete Ni bath compositions are listed in Table 2. Ni plating conditions were $4.5 \mathrm{pH}, 55^{\circ} \mathrm{C}$ temperature, $3 \mathrm{~A} / \mathrm{dm}^{2}$ cathode current density and electrolytic INCO nickel was used as anode. $\mathrm{Ni}$ and $\mathrm{Cr}$ were plated in separate cells but using the same design, the scheme used during plating is showed in Fig 1, the area ratio and distance between cathode and anode was $1: 2$ and $1.5 \mathrm{~cm}$ respectively, this for providing better primary current distribution [14].

The samples were coated with $\mathrm{Cr}$ immediately after nickel plating. Chromium plating was done at $8 \mathrm{~A} / \mathrm{dm}^{2}$ constant cathode current during 2 minutes and using graphite as the anode. UV-vis measurements were made before and after Cr plating to dilute solutions (1:20 in water) in a UNICAM UV300 between 300 and $800 \mathrm{~nm}$ to observe changes in the Cr complexes due to the electrolytic process. 
Table 1. Chromium bath composition for chromium plating.

\begin{tabular}{|c|c|c|c|c|c|c|}
\hline \multirow{3}{*}{ No } & \multirow{3}{*}{ Treatment } & \multicolumn{5}{|c|}{$\mathrm{Cr}^{+3} /\left(\mathrm{mol} \mathrm{L}^{-1}\right)=0.385$} \\
\hline & & \multicolumn{5}{|c|}{ Concentration / $\left(\mathrm{g} \mathrm{L} \mathrm{L}^{-1}\right)$} \\
\hline & & HCOONa & $\begin{array}{c}\text { CH3COONa } \\
3 \mathrm{H}_{\mathrm{O}}\end{array}$ & $\mathrm{H}_{3} \mathrm{BO}_{3}$ & $\mathrm{NaH}_{2} \mathrm{PO}_{2} \mathrm{H} 2 \mathrm{O}$ & $\mathrm{AlCl}_{3} 6 \mathrm{H}_{2} \mathrm{O}$ \\
\hline 1 & $\mathrm{Cl} /$ For & 47 & 0 & 50 & 0 & 0 \\
\hline 2 & $\mathrm{Cl} /$ For $+\mathrm{Ac}$ & 24 & 28 & 50 & 0 & 0 \\
\hline 3 & $\mathrm{Cl} /$ For $+\mathrm{P}$ & 47 & 0 & 50 & 41 & 0 \\
\hline 4 & $\mathrm{Cl} /$ For $+\mathrm{Ac}+\mathrm{P}$ & 24 & 28 & 50 & 41 & 0 \\
\hline 5 & $\mathrm{Cl} /$ For $+\mathrm{Al}$ & 47 & 0 & 50 & 0 & 29 \\
\hline 6 & $\mathrm{Cl} /$ For $+\mathrm{Ac}+\mathrm{Al}$ & 24 & 28 & 50 & 0 & 29 \\
\hline
\end{tabular}

Table 2. Watts bath composition for nickel plating.

\begin{tabular}{|c|c|}
\hline Compound & Concentration $/\left(\mathrm{g} \mathrm{L}^{-1}\right)$ \\
\hline $\mathrm{NiSO}_{4} \cdot 6 \mathrm{H}_{2} \mathrm{O}$ & 250 \\
\hline $\mathrm{NiCl}_{2} \cdot 7 \mathrm{H}_{2} \mathrm{O}$ & 60 \\
\hline $\mathrm{H}_{2} \mathrm{BO}_{3}$ & 40 \\
\hline $\mathrm{C}_{12} \mathrm{H}_{25} \mathrm{NaO}_{4} \mathrm{~S}$ & 1 \\
\hline$\left(\mathrm{NH}_{2}\right)_{2} \mathrm{CS}$ & 0.25 \\
\hline $\mathrm{C}_{7} \mathrm{H}_{4} \mathrm{NNaO}_{3} \mathrm{~S} \cdot 2 \mathrm{H}_{2} \mathrm{O}$ & 1 \\
\hline
\end{tabular}

Figure 1. Nickel and chromium plating scheme.

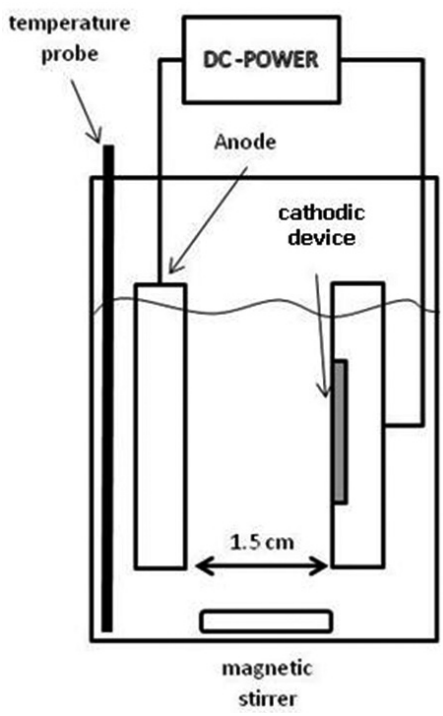

2.4 Thickness measurements.

Chromium films thickness was measured by the coulometric method using the same three-electrode cell used for corrosion measurements; but for this case the solution was $100 \mathrm{~g} / \mathrm{L}$ sodium sulfate and the anode current density was $0.1 \mathrm{~A} / \mathrm{dm}^{2}$ as in [12]. Dissolved mass was calculated assuming only oxidation reaction on the electrode as in Equation 1. On the other hand, the cathode efficiency during plating was calculated as the stripped/deposition charge ratio.

$$
\mathrm{Cr} \rightarrow \mathrm{Cr}^{+6}+6 \mathrm{e}^{-} \mathrm{Ec} 1 .
$$

2.4 Coating characterization

A Leyca Stereoscan 940 scanning electron microscope (SEM) was used to investigate the original surface of the coating and the surface after the corrosion. The coating elemental composition was determined using an energy dispersive X-ray spectroscope (EDX) attached to the SEM, using a $20 \mathrm{KeV}$ electron beam. A Siemens D5000 X-ray difractometer was used for studying the crystalline texture.

\section{RESULTS AND DISCUSSION}

\subsection{UV-visible spectra}

The UV-vis spectra was used for determining the role of the compounds in the Cr bath solution. Figure 2(a) shows the UV-vis spectra for the Cr baths before plating. Two peaks can be seen, corresponding to trivalent chromium complexes; these appeared between 416-428 nm and 578-582 nm. Such peaks were close to those reported in $[8,15-16]$ for trivalent $\mathrm{Cr}$ complexes with organic ligands; small shifts between peaks were observed between all solution formulations due to the different complexes formed. Figure 2(b) shows the UV-vis spectra for the $\mathrm{Cr}$ baths after plating, where two peaks corresponding to trivalent chromium appeared in similar wavelengths as before plating. However, a change in the region near 366-368 nm is clearly observed. This could have been caused by $\mathrm{Cr}(\mathrm{III})$ to $\mathrm{Cr}(\mathrm{VI})$ oxidation which has a strong absorbance (close to $362 \mathrm{~nm}$ ) [17]. Such oxidation can occur in the graphite anode as a parallel reaction. When hypophosphite is present it acts as $\mathrm{Cr}$ (VI) reducer, meaning that the shift is less evident for plating solutions containing hypophosphite than for solutions without a reducer agent.

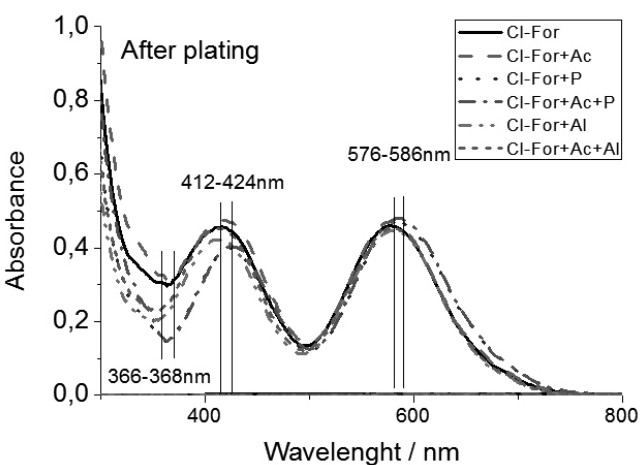

a)

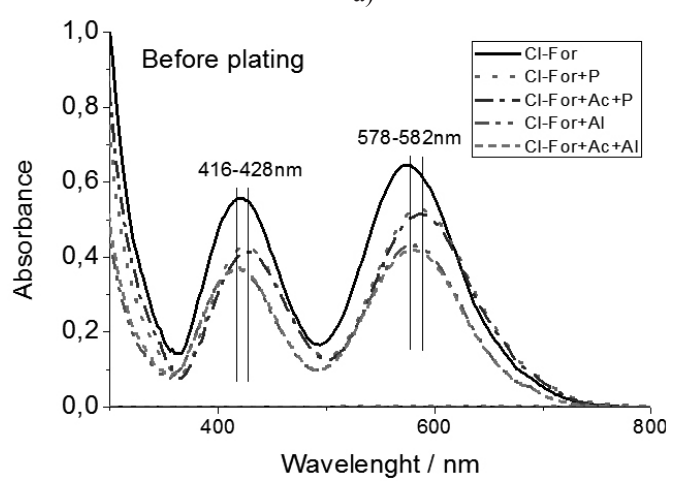

b)

Figure 2. UV-vis spectra of $\mathrm{Cr}(\mathrm{III})$ solutions with different compositions at $\mathrm{pH}$ 3.5: (a) before plating; (b) after plating. 
1.2 Composition and surface morphology.

EDX analysis was performed on the Cr films obtained from the different solutions shown in table 1, nickel coating was also analyzed as control, and results are shown in the table 3 . The elements presents were: iron from the substrate and nickel and sulfur from the previous Ni layer (sulfur appeared due to the incorporation in the coating from the brighteners used in the solution). Chromium and oxygen were also detected and correspond to the $\mathrm{Cr}$ film composition, it can be seen because in nickel coating no oxygen was found, thus ruling out the possibility that the latter corresponds to a native oxide film. The quantity of $\mathrm{Cr}$ detected by EDX correlated with the film thickness, the variation observed between $\mathrm{Cr}$ deposited from each solution mean that any chemical system would modify the $\mathrm{Cr}$ reduction process and thus cathode efficiency during plating. The greatest amount of chromium was detected when only formate was used as the complexing agent; the addition of acetate, hypophosphite and aluminum to the formulation leads to a reduction in chromium content. It can be seen that oxygen was incorporated into all samples, perhaps in the form of an oxide or hydroxide due to the $\mathrm{pH}$ increase in the cathode during the electrode reaction. Phosphorus was also incorporated to the coatings when hypophosphite was added to the solution, as found by XPS analysis in [9-11]. On the other hand, aluminum was not detected by EDX measurements in coatings obtained from solutions containing $\mathrm{AlCl}_{3}$.

Table 3. EDX analysis of chromium films obtained from different solution compositions.

\begin{tabular}{|c|l|c|c|c|c|c|c|}
\hline \multicolumn{2}{|c|}{ Treatment } & \multicolumn{7}{|c|}{ Element (w\%) } \\
\cline { 3 - 8 } & $\mathrm{Cr}$ & $\mathrm{O}$ & $\mathrm{P}$ & $\mathrm{Ni}$ & $\mathrm{S}$ & $\mathrm{Fe}$ \\
\hline 0 & Nickel (control) & -- & -- & -- & 96.6 & 0.85 & 2.5 \\
\hline 1 & $\mathrm{Cl} /$ For & 22.88 & 10.95 & -- & 64.05 & 0.58 & 1.55 \\
\hline 2 & $\mathrm{Cl} /$ For $+\mathrm{Ac}$ & 10.5 & 7.24 & -- & 79.13 & 0.66 & 2.47 \\
\hline 3 & $\mathrm{Cl} /$ For $+\mathrm{P}$ & 8.27 & 7.92 & 0.7 & 78.9 & 0.93 & 3.28 \\
\hline 4 & $\mathrm{Cl} /$ For $+\mathrm{Ac}+\mathrm{P}$ & 4.04 & 3.98 & 0.65 & 86.63 & 1.16 & 3.54 \\
\hline 5 & $\mathrm{Cl} /$ For $+\mathrm{Al}$ & 2.35 & 2.64 & -- & 92.08 & 0.46 & 2.47 \\
\hline 6 & $\mathrm{Cl} /$ For $+\mathrm{Ac}+\mathrm{Al}$ & 2.47 & 3.28 & -- & 90.86 & 0.32 & 3.06 \\
\hline
\end{tabular}

The morphology of the chromium coatings with different complexing agents are shown in Figure 3. It can be observed that the chromium films completely covered the substrate but for the coatings using only formate as complexant showed a porous surface. The presence of acetate produced a smooth surface; meaning that acetate probably acted as a brightener in this solution system. The surfaces of $\mathrm{Cr}$ coatings obtained in the presence of sodium hypophosphite and aluminum chloride are shown in Figure 4; both resulted in a more uniform and smooth surface. No large grains were observed in all experiments probably due to the small thickness of the coatings.

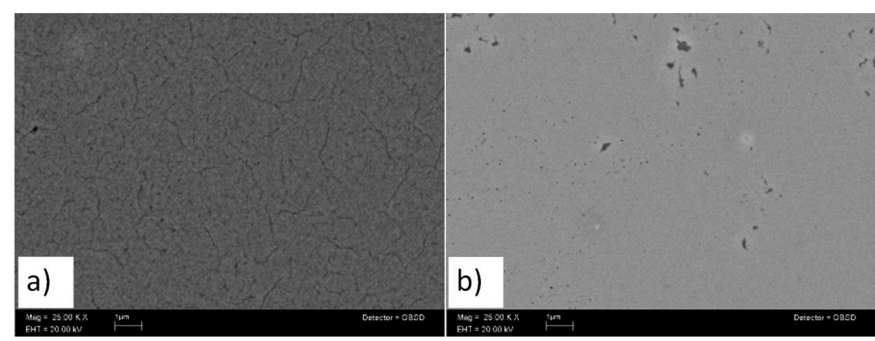

Figure 3. SEM images of chromium films obtained from: a) formate complex (Cl-For); b) formate plus acetate complex (Cl-For+Ac).

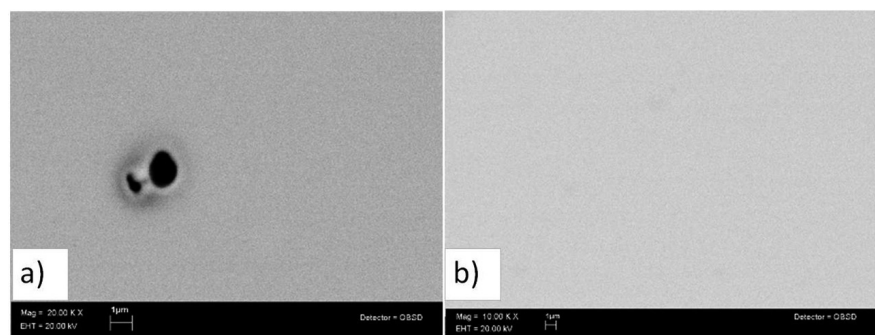

Figure 4. SEM images of chromium films obtained by adding: a) sodium hypophosphite (Cl-For+P); b) aluminum chloride (Cl-For+Ac+Al).
The figure 5, shows SEM images in the zone where chromium was stripped by coulometric method, it can be observed composition differences between upper chromium and nickel film and also there can be seen as chromium was covering completely and uniformely the nickel surface.

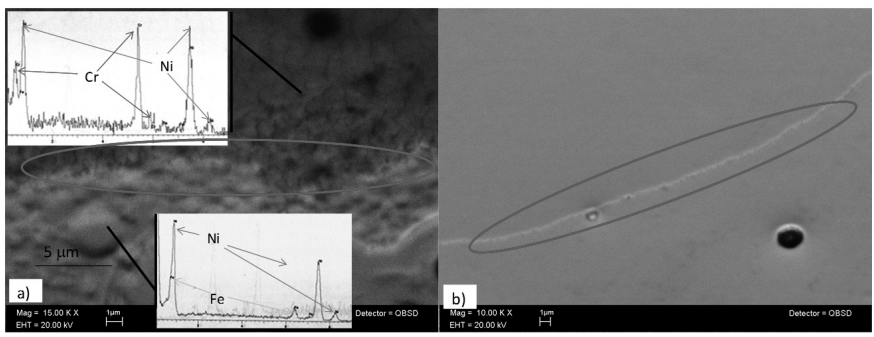

Figure 5. SEM images of chromium in striped zone after coulometric measurement at $15 \mathrm{KX}$ and inclination of $45^{\circ}$ : a) formate complex (Cl-For); b) formate plus acetate complex (Cl-For+Ac). Insert EDX spectra for different zones obtained in $\mathrm{Cl}-\mathrm{For}$ solution.

3.3 Thickness and cathode efficiency

The thicknesses of the chromium coatings measured by the coulometric method are shown in Table 4. A good correlation between the amount of $\mathrm{Cr}$ detected by EDX and the electrochemical measurement was observed. The data showed that the thickness was very low for films obtained from the solutions containing hypophosphite or aluminum chloride, as seen in EDX measurements. It can also be seen that increased thickness was obtained only when sodium formate was used as the complexant and, in for this case, the efficiency values calculated were close to those obtained for trivalent $[6,8,10$ and hexavalent chromium $[13,18]$. The low efficiencies in this process can be explained for the parallel reactions as hydrogen reduction or other solution compounds reduction. The figure 5, shows SEM images in the zone where chromium was stripped by coulometric method, there can be seen to chromium coating was completely removed during anodic process and also a little attack in nickel was done.

Table 4. Coulometric results indicating the chromium film thickness.

\begin{tabular}{|c|c|c|c|}
\hline \multicolumn{2}{|c|}{ Treatment } & Thickness (m) & Cathode efficiency (\%) \\
\hline 1 & Cl-For & $0.199 \pm 0.10$ & 8.28 \\
\hline 2 & $\mathrm{Cl}$-For/Ac & $0.122 \pm 0.10$ & 5.11 \\
\hline 3 & $\mathrm{Cl} /$ For $+\mathrm{P}$ & $0.048 \pm 0.02$ & 2.02 \\
\hline 4 & $\mathrm{Cl} /$ For $+\mathrm{Ac}+\mathrm{P}$ & $0.025 \pm 0.01$ & 1.06 \\
\hline 5 & $\mathrm{Cl} /$ For $+\mathrm{Al}$ & $0.032 \pm 0.01$ & 1.35 \\
\hline 6 & $\mathrm{Cl} /$ For $+\mathrm{Ac}+\mathrm{Al}$ & $0.030 \pm 0.01$ & 1.28 \\
\hline
\end{tabular}

3.4 Coatings structure.

$\mathrm{X}$-ray difractograms were recorded on plated coatings; the XRD patterns are shown in Figure 6. It can be seen for selected samples that there were four sharp peaks at $2 q$ angle of: $44,52.5,64$ and 77 , indicating a crystalline structure. The main peak was $\mathrm{Ni}(1,1,1)$ superimposed on $\mathrm{Cr}(1,0,0)$, also $\mathrm{Ni}(2,0,0), \mathrm{Ni}(2,2,0)$ and $\mathrm{Cr}(2,0,0)$ were observed, they corresponded to previously reported electrodeposited nickel and trivalent chromium preferential texture characteristic [19-20]. No secondary compounds as: $\mathrm{Cr}-\mathrm{O}$ (oxides or hydroxides) or Cr-P (phosphates or phosphides) peaks were identified by XRD when hypophosphite was added to the mixture perhaps due to the low cathode efficiency and film thickness or because amorphous compounds are present, meaning that no evidence was produced regarding the form in which oxygen and phosphorus were incorporated by this process. However, in other works $[10,21]$, it has been found by XPS analysis that these elements are incorporated as carbide and carboxylic groups for $\mathrm{C}$ and phosphides for $\mathrm{P}$. 


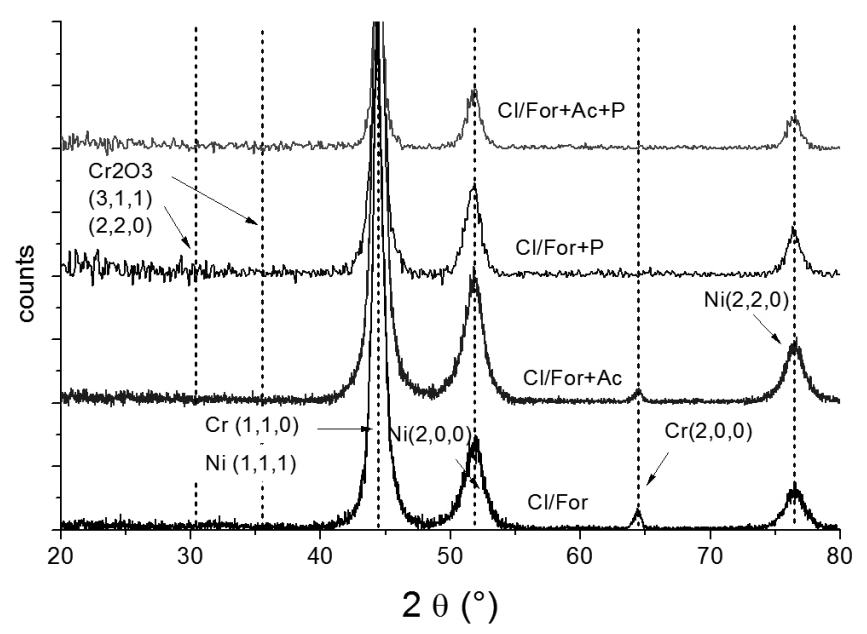

Figure 6. XRD spectra of chromium films obtained of solution of different composition.

3.5 Electrochemical impedance spectroscopy tests.

Figure 7 shows the impedance spectra in the Bode representation for electrodeposited chromium, after one and twenty four hours immersed in 3\% $\mathrm{NaCl}$. The Nyquist impedance plots (not showed) form depressed semicircles, as observed in [22]. A high impedance modulus close to $1 \mathrm{MW}$ for the first hour at low frequencies for all experiments is a common feature of these coatings. In the phase angle graph, it can be seen that all the systems had two time constants as in [23]. Two time constants correspond to different capacitive processes; one of that to the double electric layer on the surface and other to the capacitor formed for the passivated Cr oxide layer [24]. Different behavior was observed for the second time constant for each $\mathrm{Cr}$ deposit; this mean that different corrosion occurred on the passivated areas. When hypophosphite or aluminum were added to the solution, the phase angle had high values at low frequencies close to $50^{\circ}$; this means that the electrolyte had not yet permeated to the substrate interface. Greater scattering in both impedance module and phase angle for different $\mathrm{Cr}$ deposits could be seen for the spectra after 24 hours; however, formulations containing aluminum led to coatings maintaining a high impedance modulus close to $1 \mathrm{MW}$ after $24 \mathrm{~h}$ and the $\mathrm{Cr}$ coating obtained from $\mathrm{Cl}-\mathrm{For}+\mathrm{Ac}+\mathrm{Al}$ solution also kept a $60^{\circ}$ phase angle meaning that the $\mathrm{Cr}$ film conserved its properties and provided good substrate corrosion protection. For other coatings such as those obtained from $\mathrm{Cl}-\mathrm{For}+\mathrm{Al}$ and $\mathrm{Cl}-\mathrm{For}+\mathrm{Ac}+\mathrm{P}$ solutions, the Bode plots showed high impedance values but lower phase angles, meaning that corrosion products had formed on the surface, thereby increasing impedance value but that such coating had been degraded by the electrolyte. Coatings obtained from $\mathrm{Cl}-\mathrm{For}$ and $\mathrm{Cl}-\mathrm{For}+\mathrm{P}$ had the poorest performance (i.e. lowest impedance modules and phase angles). Experimental data were simulated by the circuit shown in Figure 8. This is the usual kind of circuit used for multi layer coatings [24], parameters are listed in Table 5; where $R_{s}$ represents the circuit's total ohmic resistance, $R_{c}$ porous resistance and $\mathrm{CPE}_{\mathrm{dl}}$ (constant phase element) double layer capacitance with correction for the surface roughness and $\mathrm{R}_{\mathrm{f}}$ and $\mathrm{CPE}_{\mathrm{f}}$, respectively, the film resistance and coating capacitance. Good fit is observed between experimental and model, parameters show to $R_{r}$ is the greatest resistance with respect to $R$ and for this reason can be the control resistance in the process of corrosion, differences in this parameter for every coating (of the order of $1 \times 10^{6}$ for Cl-For+Al vs. $1 \times 10^{4}$ for Cl-For) can be observed as differences in the capacity protection of the chromium film. Time dependence of $\mathrm{R}_{\mathrm{f}}$ parameter is evident and can be seen it decreases after 24 hours. For all coatings resistance values are greater than observed for hexavalent chromium coatings in other works, which are of the order of $1 \times 10^{4} \mathrm{~W} \mathrm{~cm} 2$ [22]; this indicates to corrosion performance of coatings obtained with trivalent chromium is good with respect to traditional chromium plating.
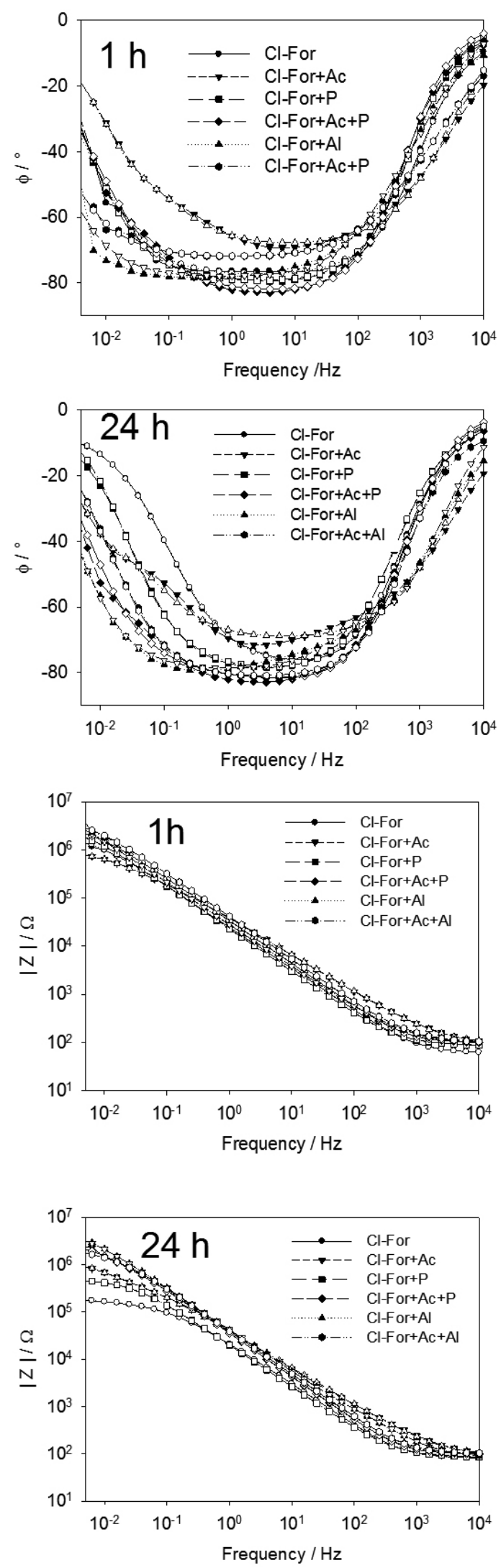

Figure 7. Bode plots for electrodeposited chromium from different solutions after 1 and 24 hours immersed in $3 \% \mathrm{NaCl}\left(0.2 \mathrm{~cm}^{2}\right.$ exposed area); filled symbols experimental, empty symbols fit. 

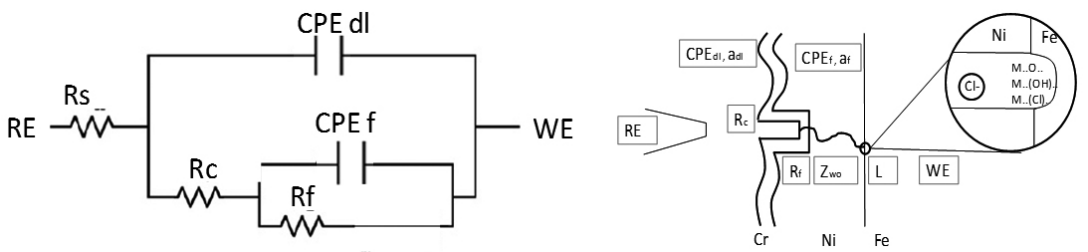

Fig 8. a) Equivalent circuit used to fit corrosion resistance parameters in EIS tests. b) physical equivalent.

Table 5. Parameters for equivalent circuit fited for EIS tets.

\begin{tabular}{|c|c|c|c|c|c|c|c|c|}
\hline Treatment & $\begin{array}{l}\text { Time } \\
\text { (h) }\end{array}$ & $\begin{array}{c}R_{s} \\
\left(\mathrm{ohm} \mathrm{cm}^{2}\right)\end{array}$ & $\begin{array}{c}C P E_{d l} \\
\left(S^{*} S^{a} \mathrm{~cm}^{-2}\right)\end{array}$ & $a_{d l}$ & $\begin{array}{c}R_{c} \\
\left(\mathrm{ohm} \mathrm{cm}^{2}\right)\end{array}$ & $\begin{array}{c}C P E_{f} \\
\left(S^{*} s^{a} \mathrm{~cm}^{-2}\right)\end{array}$ & $a_{f}$ & $\begin{array}{c}R_{f} \\
\left(\mathrm{ohm} \mathrm{cm}^{2}\right)\end{array}$ \\
\hline \multirow[t]{2}{*}{$\mathrm{Cl}^{-} /$For } & 1 & 16 & $3,95 \mathrm{E}-05$ & 0,87 & $3,74 \mathrm{E}+02$ & $2,29 \mathrm{E}-06$ & 0,57 & $4,77 \mathrm{E}+04$ \\
\hline & 24 & 18,6 & $1,98 \mathrm{E}-04$ & 0,87 & $5,70 \mathrm{E}+02$ & $1,91 \mathrm{E}-05$ & 0,25 & $4,90 \mathrm{E}+04$ \\
\hline \multirow[t]{2}{*}{$\mathrm{Cl} /$ For $+\mathrm{Ac}$} & 1 & 16,2 & $3,25 \mathrm{E}-05$ & 0,74 & $1,67 \mathrm{E}+02$ & $1,46 \mathrm{E}-06$ & 0,97 & $1,93 \mathrm{E}+05$ \\
\hline & 24 & 17,4 & $1,63 \mathrm{E}-04$ & 0,74 & $6,54 \mathrm{E}+02$ & 9,32E-08 & 1 & $2,22 \mathrm{E}+05$ \\
\hline \multirow[t]{2}{*}{$\mathrm{Cl} /$ For $+\mathrm{P}$} & 1 & 17 & $3,07 \mathrm{E}-05$ & 0,87 & $1,32 \mathrm{E}+02$ & $3,23 \mathrm{E}-06$ & 0,94 & $5,55 \mathrm{E}+05$ \\
\hline & 24 & 16,8 & $1,62 \mathrm{E}-05$ & 0,94 & $3,56 \mathrm{E}+02$ & $4,81 \mathrm{E}-08$ & 0,78 & $1,39 \mathrm{E}+05$ \\
\hline \multirow[t]{2}{*}{$\mathrm{Cl} /$ For $+\mathrm{Ac}+\mathrm{P}$} & 1 & 19,2 & $2,77 \mathrm{E}-05$ & 0,89 & $7,12 \mathrm{E}+02$ & $1,61 \mathrm{E}-06$ & 0,59 & $6,80 \mathrm{E}+05$ \\
\hline & 24 & 20 & $1,38 \mathrm{E}-04$ & 0,89 & $8,31 \mathrm{E}+01$ & 2,93E-06 & 0,39 & $9,10 \mathrm{E}+05$ \\
\hline \multirow[t]{2}{*}{$\mathrm{Cl} /$ For $+\mathrm{Al}$} & 1 & 17 & $1,46 \mathrm{E}-05$ & 0,87 & $6,77 \mathrm{E}+02$ & $6,41 \mathrm{E}-06$ & 0,89 & $4,34 \mathrm{E}+06$ \\
\hline & 24 & 17,4 & $1,62 \mathrm{E}-05$ & 0,82 & $4,56 \mathrm{E}+02$ & $3,21 \mathrm{E}-05$ & 0,89 & $1,10 \mathrm{E}+06$ \\
\hline \multirow[t]{2}{*}{$\mathrm{Cl} / \mathrm{For}+\mathrm{Ac}+\mathrm{Al}$} & 1 & 19,6 & $2,16 \mathrm{E}-05$ & 0,88 & $1,91 \mathrm{E}+02$ & $1,76 \mathrm{E}-06$ & 1,00 & $8,19 \mathrm{E}+05$ \\
\hline & 24 & 20,4 & $1,08 \mathrm{E}-04$ & 0,88 & $2,16 \mathrm{E}+01$ & $5,11 \mathrm{E}-06$ & 0,99 & $4,02 \mathrm{E}+05$ \\
\hline
\end{tabular}

3.6 Corroded surface morphology.

Figure 9 shows SEM images obtained after the EIS experiments. It can be seen in the micrographs that corrosion produced a crack pattern in the deposits obtained from $\mathrm{Cl}-\mathrm{For}+\mathrm{Ac}$ and $\mathrm{Cl}-\mathrm{For}+\mathrm{Ac}+\mathrm{P}$ solutions (the same behavior was found for $\mathrm{Cl}-\mathrm{For}$ and $\mathrm{Cl}-\mathrm{For}+\mathrm{P}$ ). This might have been caused by intergranular corrosion, as proposed for Zeng [21], due to differences between metallic $\mathrm{Cr}$ grains and $\mathrm{Cr}$ carbide as these elements produce anodic zones and the interfaces between $\mathrm{Cr}$ carbides and passive films may act as channels for chlorine ions to penetrate the passive film and erode the bulk. Different sized attacks were observed for each $\mathrm{Cr}$ deposit, depending on the formulation used to produce the coatings. The greatest damage was observe in the case of solutions having only formate or formate plus acetate, whilst adding hypophosphite resulted in less exposed area due to Cr-P compounds passive behavior. Small pits and no crack pattern were observed when aluminum chloride was used as the buffer despite these films being thinner than those produced by others $\mathrm{Cr}$ solutions. This was not completely understood but may have been caused for the $\mathrm{pH}$ stabilization on the electrode surface during plating, which might limit the incorporation of other elements on the matrix. As the $\mathrm{pH}$ in the vicinity of the cathode increased due to hydrogen ion reduction, $\mathrm{AlCl}_{3} \cdot 6 \mathrm{H}_{2} \mathrm{O}$ form $\left[\mathrm{Al}\left[\mathrm{H}_{2} \mathrm{O}\right]_{6}\right]^{+3}$ would have hydrolyzed and exerted its buffering effect to prevent hydroxyl bridged chromium (III) species formation, thereby leading to electrochemical deactivation of chromium complexes [8]. These results matched with those obtained from electrochemical impedance where the coatings obtained from solutions containing aluminum had the most corrosion resistance ( $\mathrm{R}_{\mathrm{f}}$ parameter). Moreover, Mc Dougal et al [25] have proposed that adding of $\mathrm{AlCl}_{3} \cdot 6 \mathrm{H}_{2} \mathrm{O}$ improves the consistency of the chromium deposits over the lifetime of the electrolyte buffering at around $\mathrm{pH} 5$.
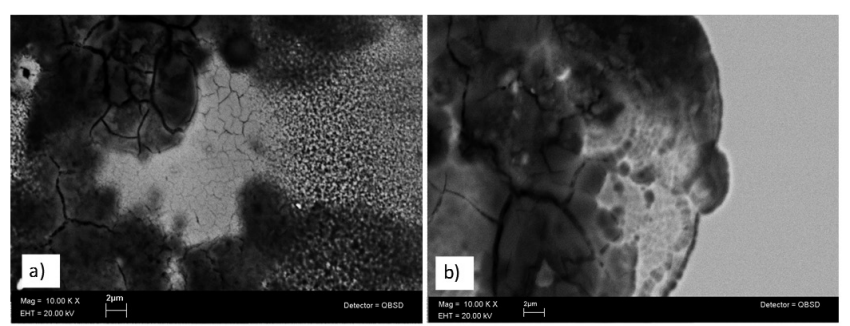

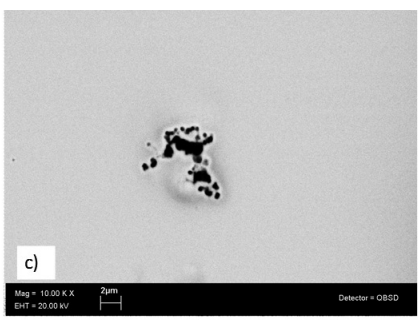

Figure 9. SEM images of chromium films after $24 \mathrm{~h}$ immersed in $3 \%$ $\mathrm{NaCl}$ : a) Cl-For+Ac; b) Cl-For+ P; c) Cl-For+Al. 10KX.

\subsection{Statistical analysis of results.}

Table 6 shows the ANOVA analysis for the total impedance module $(|\mathrm{Z}|)$ at low frequency $(5 \mathrm{mHz})$ at 1 and 24 hours of immersion in 3\% NaCl. Data was analyzed as the square root of the impedance module $\left(|Z|^{0,5}\right)$ scale to obtain normal parameter distribution and meet the statistical requirements. Analysis was done with the next factor (levels) arranged as: complex (formate and formate + acetate), additive (none, hypophosphite and aluminum) and time (1 and $24 \mathrm{~h}$ ). ANOVA table presents degree of freedom, mean squares and $\mathrm{F}$ and $\mathrm{P}$ statistics that indicate whether each factor is significant for the response variable. Results showed that complexing system has no statistical significance on total impedance $(\mathrm{P}=0.079)$ this means to corrosion resistance is independent of the use of formate or formate plus acetate as complexants. Additive and time factors had a lower $\mathrm{P}$ value $(0,009$ and 0,001 respectively), meaning that these factors had statistical significance regarding impedance module; addition of hypophosphite or aluminum chloride to the bath formulation changes the resistance of the coatings. The time dependence was obvious and for higher immersion time, the corrosion resistance tended to decrease; however, the additive used in the bath played also an important role in the resistance reached for the coating, even after 24 hours immersion, as was seen for the $\mathrm{Cr}$ coating obtained from Cl-For $+\mathrm{Ac}+\mathrm{Al}$ solution in both Bode plots (Fig 5) and SEM images (Fig 6). The $\mathrm{R}^{2}$ parameter means to just $61,95 \%$ of the response $(|\mathrm{Z}|)$ is explained by the parameters used in this study. 
Table 6. ANOVA $(\mathrm{a}=0.05)$ analysis for $\operatorname{Mod}|\mathrm{Z}|^{0.5}$

\begin{tabular}{|c|c|c|c|c|}
\hline Factor & $\begin{array}{c}\text { Degrees } \\
\text { of } \\
\text { Freedom }\end{array}$ & $\begin{array}{c}\text { Mean } \\
\text { Squares }\end{array}$ & F & P \\
\hline Complex & 1 & 440597 & 3.44 & 0.079 \\
\hline Aditive & 2 & 1578287 & 6.16 & 0.009 \\
\hline Time & 1 & 1941931 & 15.17 & 0.001 \\
\hline Error & 19 & 2432748 & & \\
\hline
\end{tabular}

$\mathrm{S}=357 \quad \mathrm{R}^{2}=61.95 \% \quad \mathrm{R}^{2}$ (adjusted) $=53.94 \%$

\section{CONCLUSIONS}

$\mathrm{Cr}$ coatings having acceptable quality were deposited from $\mathrm{Cr}$ (III) baths containing carboxylic ions as main complexing system. Hypophosphite and aluminum chloride were also used for modifying the plating solutions chemical behavior and the features of the $\mathrm{Cr}$ coatings so obtained. Differences in morphology were observed depending on the formulation used; smooth surfaces could be seen when sodium acetate, hypophosphite and aluminum were added. Differences in the quantity of chromium deposited were found by EDX and coulometric methods meaning that kinetic parameters were also modified by the presence of different compounds in the solution.

The chromium coating corrosion resistance studied by EIS experiments in $3 \% \mathrm{NaCl}$ electrolyte showed that differences between chemical composition and morphology also modified the electrochemical behavior and the coatings obtained in the presence of aluminum chloride had the best corrosion resistance. Intergranular corrosion could be seen by EDX in the coatings obtained from solutions without aluminum chloride as buffer agent. ANOVA analysis of the data showed that additive and time factors were statistically significant while complexing system was not important for determining the coatings corrosion resistance.

\section{ACKNOWLEMENTS}

The authors would like to thank Dr. David Turcio for technical assistance, The División de Investigación-Universidad Nacional de Colombia project 202010010654 and the Red de Macrouniversidades de America Latina y el Caribe for MsC support, The CONACYT project P45833 the DGAPA-UNAM project IN102907 for economical support and Alfacrom Ltda.

\section{REFERENCES}

[1] European Commission, Integrated pollution prevention and control reference document on best available techniques for the surface treatment of metals and plastics, 2006; pp 48-51.

[2] O. Suarez, Ingeniería e Investigación. 26 (2), 75-83, (2006)

[3] O. Suarez, J. Olaya, et al, Rev. LatinAm. Metal. Mater. S1 (4), 1575-1583, (2009)

[4] J. Szyncarzuk. et al, Electrochimica Acta. 33(4), 589-592, (1998)

[5] J. Szyncarzuk, et al, Electrochimica Acta 34(3), 399-403, (1989)

[6] Y.B. Song, D.T. Chin, Electrochemica Acta 48 (4), 349-356, (2002)

[7] E.G. Vinokurov, A.V Demidov, V.V Bondar, Russian Journal of coordination chemistry. 31(1), 17-21, (2005)

[8] A. Baral, R. Engelken, J. Electrochem. Soc. 152 (7), C504-C512 (2005)

[9] S. Surviliene, V. Jasulaitiene, O. Nivinskiene, A. Cesuniene, Appl. Surface Sci. 253 (16), 6738-6743, (2007)

[10] L. Baosong, et al, Surface and coating technology. 201, 2578-2586, (2006)

[11] S. Surviliene, O. Nivinskiene, et al, J. Appl. Electrochem. 36, 649-654, (2006)

[12] ASTM B 504-90. Standard test method for measurement of thickness of metallic coatings by the coulometric method. ASTM; 1995.

[13] S. Mordechay in Modern electroplating. Electrodeposition of chromium, D. Snyder, NV. Mandic, Wiley, 1974; Cap 7.

[14] D. Pletcher, Industrial electrochemistry, Chapman and Hall; New York 1990.

[15] L. Baosong, A. Lin, et al, Journal of alloys and compounds. 453, 93-101 (2008)

[16] Z. Zeng, Y. Sun, J. Zhang, Electrochemistry Communications. 11, 331334 (2009)

[17] D. L. Rodman, A. Nathan, et al, Talanta. 70(3), 668-675, (2006)

[18] D. Snyder, R. Jones, Surface Finished 215-216, (2004)

[19] C. A. Huang, C. Y. Cheng, Surface \& coating technology. 203, 3320$3324,(2009)$

[20] Chin An Huang. Yu Wey Liu, C. H. Chuang, Thin solids films. 517, 49024904 (2009)

[21] Z. Zeng, A. Liang, J. Zhang, Electrochimica Acta. 53, $7344-7349$ (2008)

[22] G. Saravanan . S. Mohan, Corrosion science 51, 197-202 (2009)

[23] J. Y. Lee, M. Kim, et al, Trans. Nonferrous Met. Soc. China 19, 819-823, (2009)

[24] H. Kaesche, Corrosion of metals, Physicochemical principles and current problems, Springer; 2003.

[25] J. Mc Dougall, E.M Shafif, J. Appl. electrochem. 28, 929-934, (1998) 